\title{
Editorial
}

Epidemiology

Diabetes Metab J 2014;38:194-196

http://dx.doi.org/10.4093/dmj.2014.38.3.194

pISSN 2233-6079 • eISSN 2233-6087

DIABET\&S \& METABOLISM JOURNAL

\section{It's Still Not Too Late to Make a Change: Current Status of Glycemic Control in Korea}

\author{
Sang Yong Kim \\ Department of Endocrinology and Metabolism, Chosun University Hospital, Chosun University School of Medicine, Gwangju, Korea
}

Diabetes is an important chronic disease causing economic and social burden around the world. The prevalence of diabetes in Korea has profoundly increased from 1.5\% to $12.4 \%$ over the past 40 years. Recent studies demonstrated that the prevalence of diabetes and prediabetes were $12.4 \%$ (men, $14.5 \%$; women, $10.4 \%$ ) and $38.3 \%$ (men, $41 \%$; women, $35.7 \%$ ), respectively [1,2]. This outburst of diabetes in Korea is caused by rapid economic development, dramatic changes in lifestyle, and increased aging population. Diabetes is associated with chronic diseases such as hypertension, dyslipidemia, and various other complications including macrovascular diseases as well as microvascular diseases [3]. These diseases are often the direct causes of death in patients with diabetes. Diabetes itself is the 5th leading cause of death in Korea and also influences other causes of death such as cardiovascular and cerebrovascular diseases [4]. The most serious fact is that the frequency of diabetic complications is also increasing along with the increment of prevalence of diabetes. In a Korean National Diabetes Program, 43.2\% diabetic patients had hypertension, 34.8\% had dyslipidemia, $10.8 \%$ had macrovascular disease, and 16.7\% had microvascular diseases [5]. Recently, Korean Diabetes Association published "Diabetes Fact Sheet in Korea 2013." According to this report, more than half of the diabetic patients have hypertension (54.6\%) and dyslipidemia (79.6\%) and one-third of diabetic patients also have microvascular disease such as nephropathy (27.3\%), neuropathy (33.5\%), or retinopathy (18.6\%) [6]. Complications do not only affect the quality of life and mortality of patients with diabetes but are also associated with higher direct medical costs. Diabetic patients with microvascular complications spend up to 4.7 times as much, patients with macrovascular complications up to 10.7 times as much, and patients with both complications spend 8.8 times as much compared to those with no complications. The medical cost of diabetes mellitus covered by the national health insurance corporation is 3.2 trillion won which accounts for $19.2 \%$ of all medical costs [7].

Diabetic complications are strongly related with the degree of glycemic control. Many studies demonstrated that an adequate glycemic control is mandatory for preventing diabetic complication. The United Kingdom Prospective Diabetes Study and the Kumamoto study showed that early intensive glycemic control can delay the onset and progression of diabetic retinopathy, nephropathy, and neuropathy compared with conventional treatment $[8,9]$. In the Steno-2 study, the intensive therapy group had a $46 \%$ lower risk for all-cause mortality and a $57 \%$ lower risk of death from cardiovascular causes [10]. However, adequate glycemic control is not easily achieved in real clinical settings. Actually, adequate glycemic control was achieved in only $43.5 \%$ and $22.9 \%$ rate with the use of target hemoglobin A1c (HbAlc) level of $<7.0 \%$ and $<6.5 \%$, respectively, according to the data from Korea National Health and Nutrition Examination Survey (KNHANES) 2005 [11]. These data means that more than half of the diabetic patients are prone to develop diabetic complications. Therefore, it is crucial to devise a plan-of-action to alleviate this situation in one way or another.
Corresponding author: Sang Yong Kim

Department of Endocrinology and Metabolism, Chosun University Hospital, Chosun University School of Medicine, 365 Pilmun-daero, Dong-gu, Gwangju 501-717, Korea

E-mail: diabetes@chosun.ac.kr
This is an Open Access article distributed under the terms of the Creative Commons Attribution Non-Commercial License (http://creativecommons.org/licenses/by-nc/3.0/) which permits unrestricted non-commercial use, distribution, and reproduction in any medium, provided the original work is properly cited. 
In this issue, Jeon et al. [12] investigated the level of glycemic control and the factors associated with glycemic control using the data from the KNHANES V (2010 to 2012). In this report, $45.6 \%$ of diabetic patients reached the target of $<7.0 \%$ and $27 \%$ reached $<6.5 \% \mathrm{HbA} 1 \mathrm{c}$ level. Compared with a previous report from KNHANES 2005, slightly more diabetic patients reached their respective targets. However, more than half of the patients still fail to reach the target and the average HbA1c level was 7.39\%. The average HbA1c level increased according to the increment of diabetic duration from $7.15 \%$ to $7.79 \%$. These data are very disappointing considering the fact that the medical circumstances have changed since the KNHANES 2005 investigation. Several guidelines and recommendations have been published for glycemic control as well as management and education of diabetic complications. Most recommendations emphasize that early and proactive therapy should be applied to all diabetic patients, including newly diagnosed patients. Moreover, newly developed agents such as DPP-4 inhibitor, GLP-1 analogues, and insulin analogues have been introduced in clinical fields. These agents have characteristics that are associated with low incidence of hypoglycemia and weight benefit compared to traditional antidiabetic agents. Therefore, although the medical milieu has improved over the previous several years, the success rate of reaching the target $\mathrm{HbA1c}$ level is still unchanged. In other words, the majority of diabetic patients did not benefit from any of these changes.

Why is it that many diabetic patients do not reach the glycemic goal despite the improvements of medical circumstances? Among many reasons, the unique characteristics of diabetes may be one of the important factors for this phenomenon. Type 2 diabetes has complex pathophysiologies which are represented as insulin resistance and $\beta$-cell dysfunction. Because many different factors contribute to hyperglycemia, it is not possible to control blood glucose with a single method. In addition, adequate glycemic control means not only preventing hyperglycemia, but also hypoglycemia. Hypoglycemia is an important complication of glucose-lowering therapy and a major limiting factor disturbing adequate glycemic control. Attempts to intensively control glycemic levels invariably increase the risk of hypoglycemia. Moreover, diabetes itself is a chronic progressive disease. As the duration of diabetes increases, $\beta$-cell function usually deteriorates. It means that if the duration of diabetes is prolonged, the variability of glucose widens and results in poor glycemic control [13], which is consistent with this report showing that the average HbAlc level increased according to the incremental diabetic duration. Therefore, we need to establish a plan to improve glycemic control and reduce diabetic complications. First of all, a complete medical evaluation should be performed in all diabetic patients. Most guidelines recommend that all diabetic patients to check their level of glycemic control as well as status of complications regularly. In order to make the best judgment for individual therapy, complete knowledge of the patient's medical status is undoubtedly required. Moreover, it is important to find preexisting complications, but it is more important to identify patients with diabetes who are at risk of rapid progression of $\beta$-cell decline and premature development of vascular complications since it might be an opportunity to minimize future occurrences of diabetic complications. Secondly, patient-tailored therapy should be installed in real clinical field. According to recent large clinical trials, tightly regulating glycemic levels to bring it close to the normal range may not be appropriate in some type 2 diabetic patients. In patients with a long duration of diabetes or those who have high risks of cardiovascular diseases, we need to be cautious as to not bring about serious side effects through tight control. On the contrary, intensive glycemic control usually decreases vascular complications in newly diagnosed patients. In addition, a legacy effect was observed after 10 years of trial in the rate of vascular complications and mortality. Therefore, all diabetic patients require individually established goals for blood glucose values according to their status. We need to weigh the benefits against risks for individual patients. Thirdly, we need to develop and establish education programs for diabetic patients, and these education programs should be thoroughly made to be systematic and standardized. Although diabetes education programs including lifestyle modifications are essential components for the management of diabetes, the effectiveness varies according to the type of education, patients' characteristics, etc. Recent data demonstrated that the effectiveness of education appears to be related to the method by which it is received rather than the education itself [14]. Moreover, the duration of diabetes is influenced the effectiveness of diabetes education [15].

In conclusion, the prevention of diabetic complications is still poor in content despite the variety of available antidiabetic agents and improved methods of assessing disease progression. However, the more the need for a change, the more we will be able to do so. We still have a chance and it is worth reflecting on this situation. We firmly believe that the several 
ongoing and upcoming studies will discover valid ways to reduce diabetic complications. We must, and will do so.

\section{CONFLICTS OF INTEREST}

No potential conflict of interest relevant to this article was reported.

\section{REFERENCES}

1. Kim DJ. The epidemiology of diabetes in Korea. Diabetes Metab J 2011;35:303-8.

2. Jeon JY, Ko SH, Kwon HS, Kim NH, Kim JH, Kim CS, Song KH, Won JC, Lim S, Choi SH, Jang MJ, Kim Y, Oh K, Kim DJ, Cha BY; Taskforce Team of Diabetes Fact Sheet of the Korean Diabetes Association. Prevalence of diabetes and prediabetes according to fasting plasma glucose and HbAlc. Diabetes Metab J 2013;37:349-57.

3. Pickup JC, Williams G. Textbook of diabetes. 3rd ed. Malden: Blackwell Science; 2003.

4. Statistics Korea: Causes of death statistics 2012. Available from: http://kostat.go.kr (updated 2013 Sep 25).

5. Rhee SY, Chon S, Kwon MK, Park Ie B, Ahn KJ, Kim IJ, Kim SH, Lee HW, Koh KS, Kim DM, Baik SH, Lee KW, Nam MS, Park YS, Woo JT, Kim YS. Prevalence of chronic complications in korean patients with type 2 diabetes mellitus based on the korean national diabetes program. Diabetes Metab J 2011;35: 504-12.

6. The Taskforce Team of Diabetes Fact Sheet of the Korean Diabetes Association. Diabetes fact sheet in Korea 2013. Seoul: Korean Diabetes Association; 2013.

7. Lee KW. Costs of diabetes mellitus in Korea. Diabetes Metab J 2011;35:567-70.

8. Ohkubo Y, Kishikawa H, Araki E, Miyata T, Isami S, Motoyoshi S, Kojima Y, Furuyoshi N, Shichiri M. Intensive insulin therapy prevents the progression of diabetic microvascular complications in Japanese patients with non-insulin-dependent diabetes mellitus: a randomized prospective 6-year study. Diabetes Res Clin Pract 1995;28:103-17.

9. UK Prospective Diabetes Study (UKPDS) Group. Intensive blood-glucose control with sulphonylureas or insulin compared with conventional treatment and risk of complications in patients with type 2 diabetes (UKPDS 33). Lancet 1998;352: 837-53.

10. Gaede P, Lund-Andersen H, Parving HH, Pedersen O. Effect of a multifactorial intervention on mortality in type 2 diabetes. N Engl J Med 2008;358:580-91.

11. Choi YJ, Kim HC, Kim HM, Park SW, Kim J, Kim DJ. Prevalence and management of diabetes in Korean adults: Korea National Health and Nutrition Examination Surveys 19982005. Diabetes Care 2009;32:2016-20.

12. Jeon JY, Kim DJ, Ko SH, Kwon HS, Lim S, Choi SH, Kim CS, An JH, Kim NH, Won JC, Kim JH, Cha BY, Song KH; the Taskforce Team of Diabetes Fact Sheet of the Korean Diabetes Association. Current status of glycemic control of patients with diabetes in Korea: the Fifth Korea National Health and Nutrition Examination Survey. Diabetes Metab J 2014;38:197203.

13. Wajchenberg BL. beta-cell failure in diabetes and preservation by clinical treatment. Endocr Rev 2007;28:187-218.

14. Ko SH, Park SA, Cho JH, Ko SH, Shin KM, Lee SH, Song KH, Park YM, Ahn YB. Influence of the duration of diabetes on the outcome of a diabetes self-management education program. Diabetes Metab J 2012;36:222-9.

15. Choi MJ, Yoo SH, Kim KR, Bae YM, Ahn SH, Kim SS, Min SA, Choi JS, Lee SE, Moon YJ, Rhee EJ, Park CY, Lee WY, Oh KW, Park SW, Kim SW. Effect on glycemic, blood pressure, and lipid control according to education types. Diabetes Metab J 2011; 35:580-6. 